\title{
p-doping-free InGaN/GaN light-emitting diode driven by three-dimensional hole gas
}

Zi-Hui Zhang, Swee Tiam Tan, Zabu Kyaw, Wei Liu, Yun Ji, Zhengang Ju, Xueliang Zhang, Xiao Wei Sun, and Hilmi Volkan Demir

Citation: Appl. Phys. Lett. 103, 263501 (2013);

View online: https://doi.org/10.1063/1.4858386

View Table of Contents: http://aip.scitation.org/toc/apl/103/26

Published by the American Institute of Physics

\section{Articles you may be interested in}

InGaN/GaN light-emitting diode with a polarization tunnel junction Applied Physics Letters 102, 193508 (2013); 10.1063/1.4806978

Investigation of $\mathrm{p}$-type depletion doping for InGaN/GaN-based light-emitting diodes Applied Physics Letters 110, 033506 (2017); 10.1063/1.4973743

Three-dimensional hole gas induced by polarization in (0001)-oriented metal-face III-nitride structure Applied Physics Letters 97, 062103 (2010); 10.1063/1.3478556

InGaN/GaN tunnel junctions for hole injection in GaN light emitting diodes

Applied Physics Letters 105, 141104 (2014); 10.1063/1.4897342

Polarization induced hole doping in graded $\mathrm{Al}_{\mathrm{x}} \mathrm{Ga}_{1-\mathrm{x}} \mathrm{N}(\mathrm{x}=0.7 \sim 1)$ layer grown by molecular beam epitaxy Applied Physics Letters 102, 062108 (2013); 10.1063/1.4792685

MBE-grown 232-270 nm deep-UV LEDs using monolayer thin binary GaN/AIN quantum heterostructures Applied Physics Letters 110, 041108 (2017); 10.1063/1.4975068

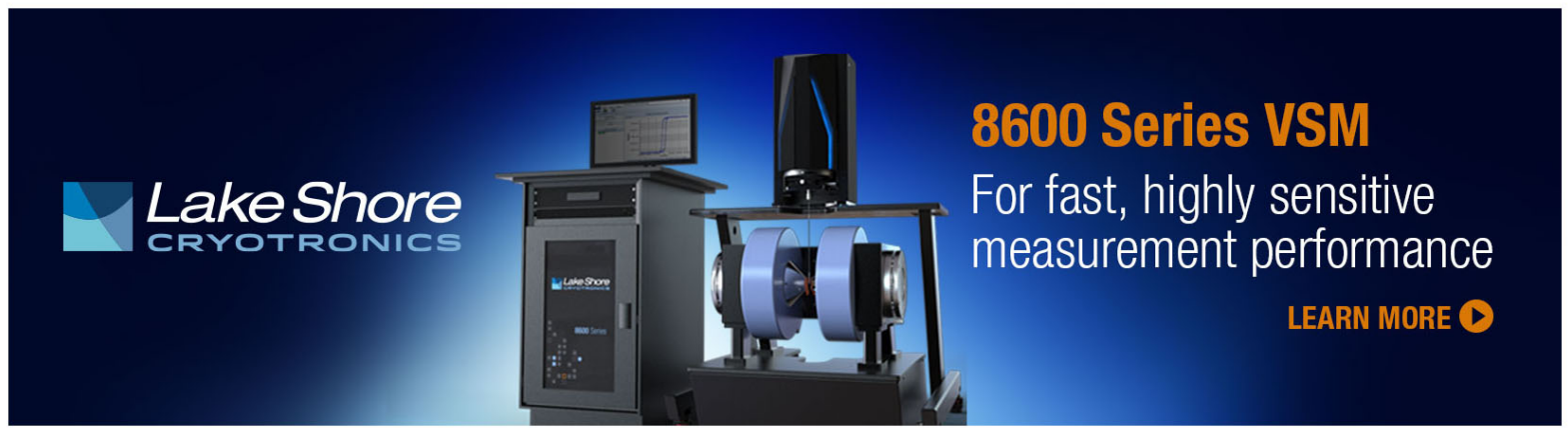




\title{
p-doping-free InGaN/GaN light-emitting diode driven by three-dimensional hole gas
}

\author{
Zi-Hui Zhang, ${ }^{1,2}$ Swee Tiam Tan, ${ }^{1,2}$ Zabu Kyaw, ${ }^{1,2}$ Wei Liu, ${ }^{1,2}$ Yun Ji, ${ }^{1,2}$ Zhengang Ju, ${ }^{1,2}$ \\ Xueliang Zhang, ${ }^{1,2}$ Xiao Wei Sun, ${ }^{1,2,3, a)}$ and Hilmi Volkan Demir ${ }^{1,2,4,5, b)}$ \\ ${ }^{1}$ LUMINOUS! Centre of Excellence for Semiconductor Lighting and Displays, School of Electrical and \\ Electronic Engineering, Nanyang Technological University, 50 Nanyang Avenue, 639798 Singapore \\ ${ }^{2}$ LUMINOUS! Centre of Excellence for Semiconductor Lighting and Displays, School of Physical and \\ Mathematical Sciences, Nanyang Technological University, 50 Nanyang Avenue, 639798 Singapore \\ ${ }^{3}$ Department of Electronics and Electrical Engineering, South University of Science and Technology of China, \\ Shenzhen, Guangdong 518055, China \\ ${ }^{4}$ Department of Electrical and Electronics, UNAM-Institute of Material Science and Nanotechnology, \\ Bilkent University, Ankara TR-06800, Turkey \\ ${ }^{5}$ Department of Physics, UNAM-Institute of Material Science and Nanotechnology, Bilkent University, \\ Ankara TR-06800, Turkey
}

(Received 12 June 2013; accepted 6 December 2013; published online 23 December 2013)

\begin{abstract}
Here, $\mathrm{GaN} / \mathrm{Al}_{x} \mathrm{Ga}_{1-x} \mathrm{~N}$ heterostructures with a graded AlN composition, completely lacking external p-doping, are designed and grown using metal-organic-chemical-vapour deposition (MOCVD) system to realize three-dimensional hole gas (3DHG). The existence of the 3DHG is confirmed by capacitance-voltage measurements. Based on this design, a $p$-doping-free InGaN/GaN light-emitting diode (LED) driven by the 3DHG is proposed and grown using MOCVD. The electroluminescence, which is attributed to the radiative recombination of injected electrons and holes in $\mathrm{InGaN} / \mathrm{GaN}$ quantum wells, is observed from the fabricated p-doping-free devices. These results suggest that the 3DHG can be an alternative hole source for InGaN/GaN LEDs besides common $\mathrm{Mg}$ dopants. @ 2013 AIP Publishing LLC. [http://dx.doi.org/10.1063/1.4858386]
\end{abstract}

For the purpose of energy-saving lighting, InGaN/GaN light-emitting diodes (LEDs) have been regarded as excellent candidates to replace incandescent and fluorescent lighting sources. ${ }^{1,2}$ To this end, tremendous efforts have been devoted to improve the LED performance through addressing various issues related to material quality, structure optimization, and device design and fabrication. ${ }^{3-12}$ Among these issues, to date a low p-type doping efficiency remains as a limiting factor, which adversely affects the LED performance. In typical p-type GaN, the resulting hole concentration is low because only $\sim 1 \%$ of $\mathrm{Mg}$ dopants are ionized at room temperature. ${ }^{6}$ To increase the ionization efficiency of the Mg dopants, a ptype GaN/AlGaN supperlattice was previously employed as the electron blocking layer. ${ }^{7,8}$ Also, the $\mathrm{Mg}$ dopants were reported to be more efficiently ionized under polarizationinduced electric fields within the supperlattice, which is known as Poole-Frenkel effect. ${ }^{9}$ Recently, it has been also reported that the hole concentration can be increased through the polarization doping. ${ }^{10,11}$ The $\mathrm{GaN} / \mathrm{Al}_{x} \mathrm{Ga}_{1-\mathrm{x}} \mathrm{N}$ heterostructures grown along the polar orientations exhibit strong spontaneous and piezo-electric polarizations. ${ }^{13}$ Such strong polarizations can induce electric fields causing significant band bending in the $\mathrm{GaN} / \mathrm{Al}_{x} \mathrm{Ga}_{1-x} \mathrm{~N}$ heterostructures. This in turn generates a thin channel in the $\mathrm{GaN}$ layer near the GaN/ $\mathrm{Al}_{x} \mathrm{Ga}_{1-\mathrm{x}} \mathrm{N}$ interface where the two-dimensional hole gas (2DHG) can be formed. ${ }^{14-16}$ The $2 \mathrm{DHG}$ can be extended into the three-dimensional hole gas (3DHG) distributing within the $\mathrm{Al}_{x} \mathrm{Ga}_{1-\mathrm{x}} \mathrm{N}$ layer where the AlN composition is graded to GaN. ${ }^{10,11}$ In the previous works (Refs. 10 and 11 ),

\footnotetext{
${ }^{\text {a)} E l e c t r o n i c ~ m a i l: ~ E X W S U N @ n t u . e d u . s g ~}$

b)Electronic mail: VOLKAN@stanfordalumni.org
}

the $\mathrm{Al}_{x} \mathrm{Ga}_{1-\mathrm{x}} \mathrm{N}$ layer with the graded AlN composition was doped with $\mathrm{Mg}$ dopants, and the strong polarization induced electric fields in the $\mathrm{Al}_{x} \mathrm{Ga}_{1-\mathrm{x}} \mathrm{N}$ layer with the graded AlN composition could increase the ionization rate of the Mg dopants through Poole-Frenkel effect, which may also contribute to the enhancement of the hole concentration. Therefore, it remains unclear if the polarization doping induced 3D hole gas plays a significant role in the enhancement of the hole concentration. In this work, we have designed and grown undoped $\mathrm{GaN} / \mathrm{Al}_{x} \mathrm{Ga}_{1-\mathrm{x}} \mathrm{N}$ heterostructures with a graded $\mathrm{AlN}$ composition. We investigated and confirmed the generation of the 3DHG in this class of heterostructures. Furthermore, we incorporated these $\mathrm{GaN} / \mathrm{Al}_{x} \mathrm{Ga}_{1-\mathrm{x}} \mathrm{N}$ heterostructures with the graded AlN composition in the InGaN/GaN multiplequantum-well (MQW) LED architecture, completely lacking $p$-doping. We observed the diode-rectifying characteristics in the current-voltage curve and the electroluminescence from such 3D hole gas driven LEDs. Being consistent with the experimental results, our simulations have theoretically shown that the 3DHG has been formed as a result of AlN composition grading in $\mathrm{Al}_{x} \mathrm{GaN}_{1-x} \mathrm{~N} / \mathrm{GaN}$ heterostructures, and more importantly, the $3 \mathrm{DHG}$ gas can be injected into quantum wells for recombination with electrons.

In our experiments, four [0001] oriented epi-structures were designed and grown by a metal-organic chemical vapour deposition (MOCVD) system, as shown in Fig. 1. The growth was initiated on c-plane sapphire substrates followed by a $30 \mathrm{~nm} \mathrm{GaN}$ as the nucleation layer. ${ }^{17}$ Then, a $4 \mu \mathrm{m}$ unintentionally n-type doped $\mathrm{GaN}$ (u-GaN) was grown. For Sample $A$, a $100 \mathrm{~nm} \mathrm{Al}_{x} \mathrm{Ga}_{1-\mathrm{x}} \mathrm{N}$ layer with $10 \%$ AlN composition was grown, which was followed by a $10 \mathrm{~nm}$ u-GaN layer. For Sample $B$, a $100 \mathrm{~nm} \mathrm{Al}_{x} \mathrm{Ga}_{1-\mathrm{x}} \mathrm{N}$ layer with the AlN 
composition linearly graded from 0.10 to 0.02 along the growth orientation was grown and then covered by a $10 \mathrm{~nm}$ u-GaN layer. Furthermore, we also grew a full LED architecture (i.e., Sample $D$ ) by using Sample $B$ as the template, on which a $10 \mathrm{~nm} \mathrm{n}-\mathrm{GaN}$ with a doping concentration of $5 \times 10^{17} \mathrm{~cm}^{-3}$ was grown as the current spreading layer for holes. ${ }^{5}$ Then, three-period $\operatorname{In}_{0.12} \mathrm{Ga}_{0.88} \mathrm{~N} / \mathrm{GaN}$ MQWs were grown, of which the well and barrier thickness are 3 and $8 \mathrm{~nm}$, respectively. Finally, a $0.3 \mu \mathrm{m} n-G a N$ layer with the doping concentration of $5 \times 10^{18} \mathrm{~cm}^{-3}$ was grown. As a reference, Sample $C$ was grown with the InGaN/GaN MQWs and the n-GaN layer on top of the u-GaN template. Following the epitaxial growths, the film quality has been characterized through high-resolution XRD, and the full-widths at half-maximum (FWHM) of the (102) and (002) X-ray diffraction peaks are around 213.5 and 216.0 arc sec, respectively. These narrow FWHM values indicate excellent crystal quality for our grown samples.

The photoluminescence (PL) measurements were conducted for Samples $C$ and $D$ using a PL mapper system (Nanometric RPM2000) to characterize the quantum well emission. The excitation wavelength of the $15 \mathrm{~mW} \mathrm{He}-\mathrm{Cd}$ laser source is $325 \mathrm{~nm}$. The device fabrication was also conducted for Samples $C$ and $D$. Diode mesas of $350 \times 350 \mu \mathrm{m}^{2}$ were obtained by reactive ion etch (RIE) to expose the u-GaN layers for Samples $C$ and $D$, respectively. Then $\mathrm{Ni} / \mathrm{Au}(5 \mathrm{~nm} / 5 \mathrm{~nm})$ was deposited on the u-GaN layers as the p-contact for the two samples. The annealing was conducted for Ni/Au at $575^{\circ} \mathrm{C}$ in the $\mathrm{O}_{2}$ ambient for $5 \mathrm{~min}$. After the growth of $\mathrm{Ni} / \mathrm{Au}, \mathrm{Ti} / \mathrm{Au}(30 \mathrm{~nm} / 150 \mathrm{~nm})$ was finally grown as the contact pads both on the $\mathrm{n}-\mathrm{GaN}$ layer and $\mathrm{Ni} / \mathrm{Au}$.

Besides, the capacitance-voltage (CV) measurements were performed for Samples $A$ and $B$ at room temperature to probe the hole gas. The CV test system used in this work is a conventional mercury-based CV measurement system (802B MDC three function mercury probe) operating at an AC frequency of $100 \mathrm{KHz}$. The area for the circular mercury probe to record the capacitance value of the tested samples is $4.582 \times 10^{-3} \mathrm{~cm}^{-2}$. Details on $\mathrm{CV}$ measurement can be found elsewhere. ${ }^{18}$

The measured capacitance is depicted as a function of the applied bias in Fig. 2(a) for both Samples $A$ and $B$. The positive bias has been applied to deplete the holes on Samples $A$ and $B$. Note that we have the $\mathrm{u}-\mathrm{GaN}$ layer under the $\mathrm{Al}_{x} \mathrm{Ga}_{1-x} \mathrm{~N}$ layer, and thus the electron gas generated below the $\mathrm{Al}_{x} \mathrm{Ga}_{1-x} \mathrm{~N}$ layer will affect our measurement. ${ }^{14-16}$ Since $C_{t}=C_{p} \times C_{n} /\left(C_{p}+C_{n}\right)$, in which $C_{t}, C_{p}$, and $C_{n}$ denote the total capacitance, the capacitance due to the hole depletion, and the capacitance due to the electron accumulation, respectively. When $C_{n} \gg C_{p}, C_{t} \approx C_{p}$. This condition can be realized when the applied bias exceeds $2 \mathrm{~V}$ for Sample $A$ and $3 \mathrm{~V}$ for Sample B. According to Fig. 2(a), we can see that the capacitance decreases with the increasing applied bias for both samples, which is due to the extension of the depletion region width. Meanwhile, we also calculated the hole concentration according to the CV curves obtained. The detailed hole concentration for Sample $B$ is shown in Fig. 2(b), along with which is the inset figure of the hole concentration given for both Samples $A$ and $B$ for comparison purposes. The inset figure in Fig. 2(b) shows that the 2D hole gas is generated and localized in the $\mathrm{GaN} / \mathrm{Al}_{0.10} \mathrm{Ga}_{0.90} \mathrm{~N}$ interface for Sample $A$, and the highest hole concentration is measured to be $\sim 10^{20} \mathrm{~cm}^{-3}$. The hole concentration is quickly reduced to $\sim 10^{16} \mathrm{~cm}^{-3}$ in the region away from the $\mathrm{GaN} / \mathrm{Al}_{0.10} \mathrm{Ga}_{0.90} \mathrm{~N}$ interface. On the contrary, the hole gas distribution is larger even across the $\mathrm{Al}_{x} \mathrm{Ga}_{1-x} \mathrm{~N}$ layer in Sample $B$. The hole concentration is $\sim 10^{19} \mathrm{~cm}^{-3}$ near the $\mathrm{GaN} / \mathrm{Al}_{0.02} \mathrm{Ga}_{0.98} \mathrm{~N}$ interface [Region I shown in Fig. 2(b)], and is flattened to $\sim 5 \times 10^{17} \mathrm{~cm}^{-3}$ across the $\mathrm{Al}_{x} \mathrm{Ga}_{1-x} \mathrm{~N}$ layer [Region II shown in Fig. 2(b)], representing the 3D hole distribution. As is known, the volume density of the polarization charge is depicted as $N_{D}^{P o l}(z)=\nabla \cdot P(z)=\partial P(z) / \partial z,{ }^{19}$ in which $P(z)$ is the polarization charge profile along the growth orientation (i.e., $z$, with the unit of $\mathrm{nm}$ ). In Sample $B$, we have linearly

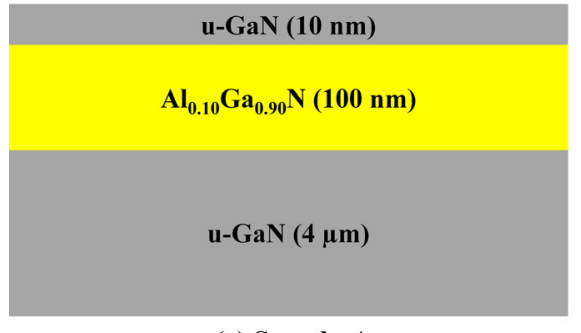

(a) Sample $A$

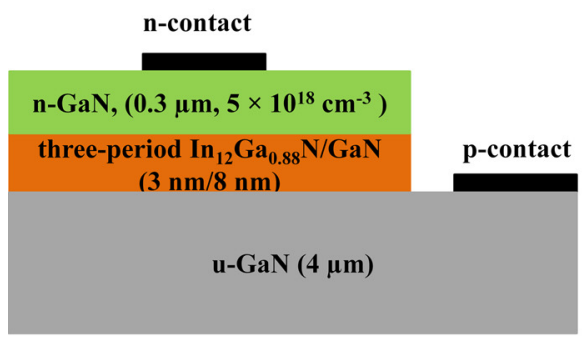

(c) Sample $C$, LED grown on u-GaN

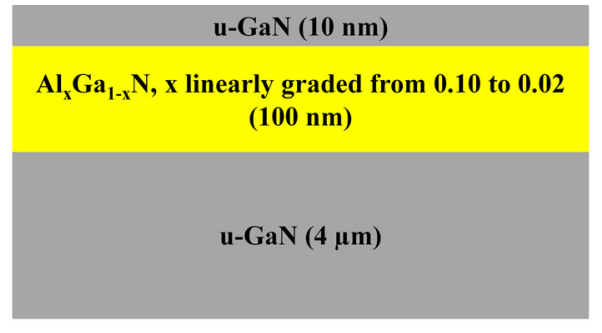

(b) Sample $B$

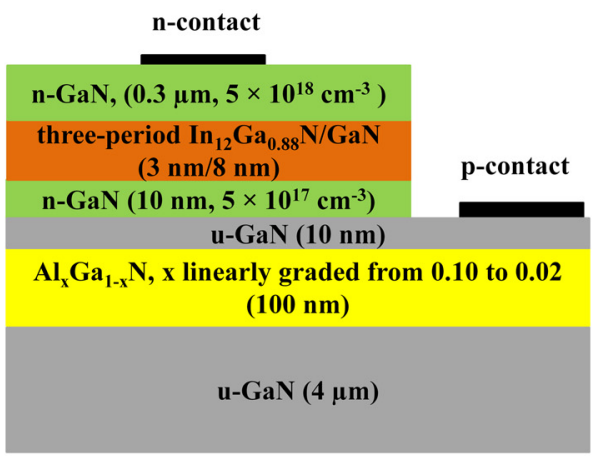

(d) Sample $D$, 3D hole gas LED grown on sample $B$
FIG. 1. (a) Sample $A$ with a $\mathrm{GaN} / \mathrm{Al}_{0.10}$ $\mathrm{Ga}_{0.90} \mathrm{~N}$ heterostructure. (b) Sample $B$ with a graded AlN composition in the $\mathrm{Al}_{x} \mathrm{Ga}_{1-x} \mathrm{~N}$ layer. (c) Sample $C$ with an InGaN/GaN LED directly grown on u-GaN template and (d) Sample $D$ with an InGaN/GaN LED grown on Sample $B$. 

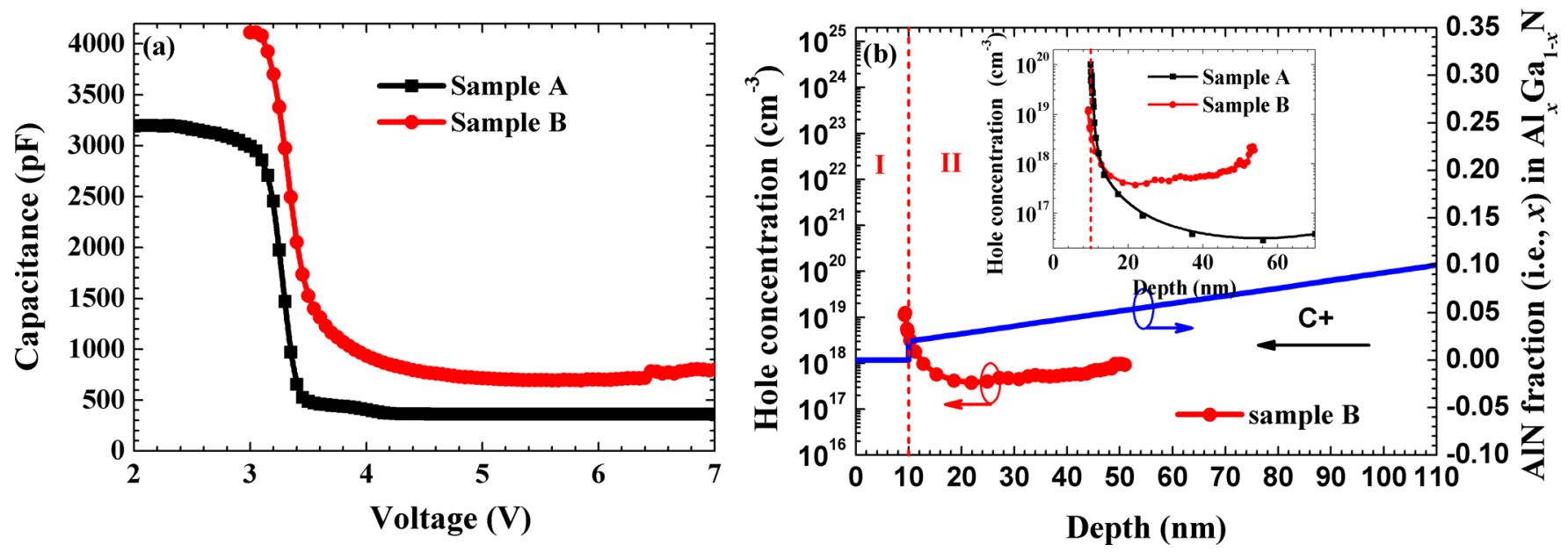

FIG. 2. (a) Capacitance versus the applied bias for Samples $A$ and $B$, and (b) calculated hole concentration for Sample $B$, and the carrier concentration for both Samples $A$ and $B$ (inset). The AlN composition (i.e., $x$ ) along the growth orientation $\left(\mathrm{C}+\right.$ ) in the $\mathrm{Al}_{x} \mathrm{Ga}_{1-x} \mathrm{~N}$ layer is also shown.

graded the AlN composition in the $\mathrm{Al}_{x} \mathrm{Ga}_{1-x} \mathrm{~N}$ layer from 0.10 to 0.02 within $100 \mathrm{~nm}$, and thus the relationship between $x$ and $z$ is $z=(-1.25 x+0.125) \times 1000$. Therefore, $N_{D}^{P o l}(z)=\nabla \cdot P(z)=(\partial P / \partial x) \times(\partial x / \partial z)$. It is known that an approximately linear relationship between the polarization charge (i.e., $P$ ) and the AlN composition (i.e., $x$ ) can be obtained. ${ }^{13}$ Note that the negative polarization induced charges pull the holes into the $\mathrm{Al}_{x} \mathrm{Ga}_{1-x} \mathrm{~N}$ layer. Thus, $N_{D}^{P o l}(z)$ can be treated as the "bulk dopants" to achieve the bulk carrier concentration, i.e., holes in this case as indicated in Region II of Fig. 2(b). Therefore, our finding shows that the $3 \mathrm{D}$ hole gas can be realized through the polarization doping in the undoped $\mathrm{GaN} / \mathrm{Al}_{x} \mathrm{Ga}_{1-\mathrm{x}} \mathrm{N}$ heterostructures with the graded AIN composition, just like the 2D hole gas formed in the previously reported abrupt undoped $\mathrm{GaN} / \mathrm{Al}_{x} \mathrm{Ga}_{1-x} \mathrm{~N}$ heterostructure interface of polar-orientations. ${ }^{20-22}$ It is believed that the native defects in the material such as Ga vacancies and the background intrinsic carriers are regarded as the hole sources. ${ }^{16,22}$ Nevertheless, we can only detect the hole concentration within the $\mathrm{Al}_{x} \mathrm{Ga}_{1-x} \mathrm{~N}$ layer for $50 \mathrm{~nm}$ according to Fig. 2(b). The strong positive bias significantly accumulates the 2D electron gas mentioned previously, and thus the electron accumulation prevents the further extension of the depletion region.

In order to better depict the physical mechanism, we have calculated the energy band diagrams and the hole gas distribution for Samples $A$ and $B$ by using APSYS, ${ }^{4}$ which selfconsistently solves the Poisson and Schrödinger equations with proper boundary conditions. In our models, we have considered the polarization induced interface charges for any heterostructure. The polarization charge density is calculated based on the models developed by Fiorentini et al. ${ }^{13}$ The polarization induced sheet charge density between the GaN and $\mathrm{Al}_{0.10} \mathrm{Ga}_{0.90} \mathrm{~N}$ layers is set to $2.43 \times 10^{12} \mathrm{~cm}^{-2}$ while the polarization induced sheet charge density of $8.74 \times 10^{11} \mathrm{~cm}^{-2}$ is assumed between the $\mathrm{Al}_{0.02} \mathrm{Ga}_{0.98} \mathrm{~N}$ layer and $\mathrm{GaN}$ cap layer for Sample $B$. Meanwhile, we have the $\mathrm{Al}_{x} \mathrm{Ga}_{1-x} \mathrm{~N}$ layer with a graded AlN composition in Sample $B$, and hence according to $N_{D}^{P o l}(z)=\nabla \cdot P(z)=(\partial P / \partial x) \times(\partial x / \partial z)$, a volume charge density of $3.58 \times 10^{17} \mathrm{~cm}^{-3}$ has been assumed in the $\mathrm{Al}_{x} \mathrm{Ga}_{1-x} \mathrm{~N}$ region. Such volume charges in the
$\mathrm{Al}_{x} \mathrm{Ga}_{1-x} \mathrm{~N}$ region with a linearly graded AlN composition are crucial, since no $3 \mathrm{DHG}$ is produced if the volume charges are lacked. In addition, the donor-type states with the energy level of Ec- $0.5 \mathrm{eV}$ have also been included in our models. ${ }^{22}$ The density of those donor-type states has been assumed to be $7 \times 10^{17} \mathrm{~cm}^{-3} \cdot{ }^{23}$ In addition, the Ga-vacancy has been considered as a p-type dopant with the deep acceptor level of $0.86 \mathrm{eV}$ above the valance band and we have set it to $0.2 \times 10^{17} \mathrm{~cm}^{-3}$ in the undoped layers. ${ }^{24,25}$ However, the calculated energy band diagrams and carrier distribution can be found in the supplementary material. ${ }^{26}$

The injection current has been measured as a function of the applied bias for the fabricated devices of Samples $C$ and $D$, as shown in Fig. 3. Sample $C$ grown on u-GaN template shows no electrical rectifying behaviour that means no pnjunction has been formed, while the diode behaviour is observed from Sample $D$. The diode behaviour for Sample $D$ indicates the formation of the pn-junction between the $\mathrm{n}$ GaN layer and the 3D hole gas in the $\mathrm{Al}_{x} \mathrm{Ga}_{1-x} \mathrm{~N}$ layer with the graded AlN composition. The turn-on voltage of Sample $D$ is about $30 \mathrm{~V}$, which is much higher than the conventional InGaN/GaN LED with the Mg doped GaN layer on the top.

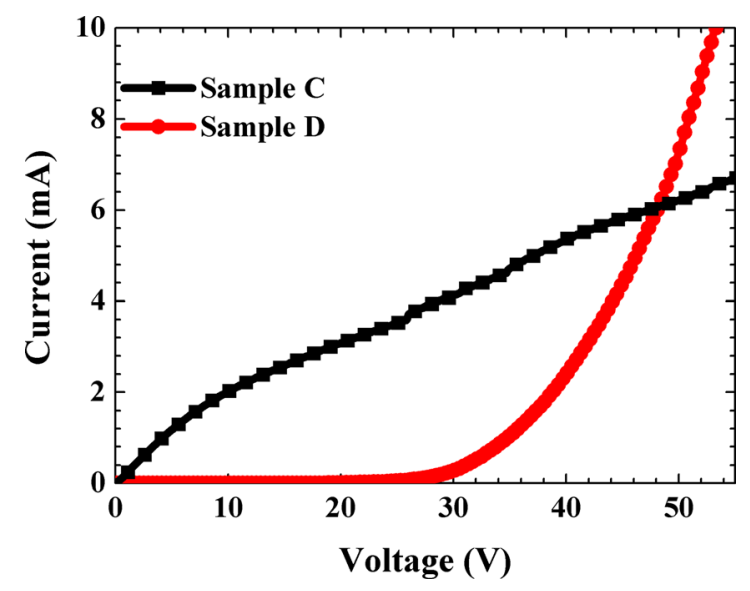

FIG. 3. Experimentally measured current as a function of the applied voltage for InGaN/GaN LED grown on u-GaN (i.e., Sample $C$ ), and InGaN/GaN LED grow on $3 \mathrm{D}$ hole gas structure (i.e., Sample $D$ ). 

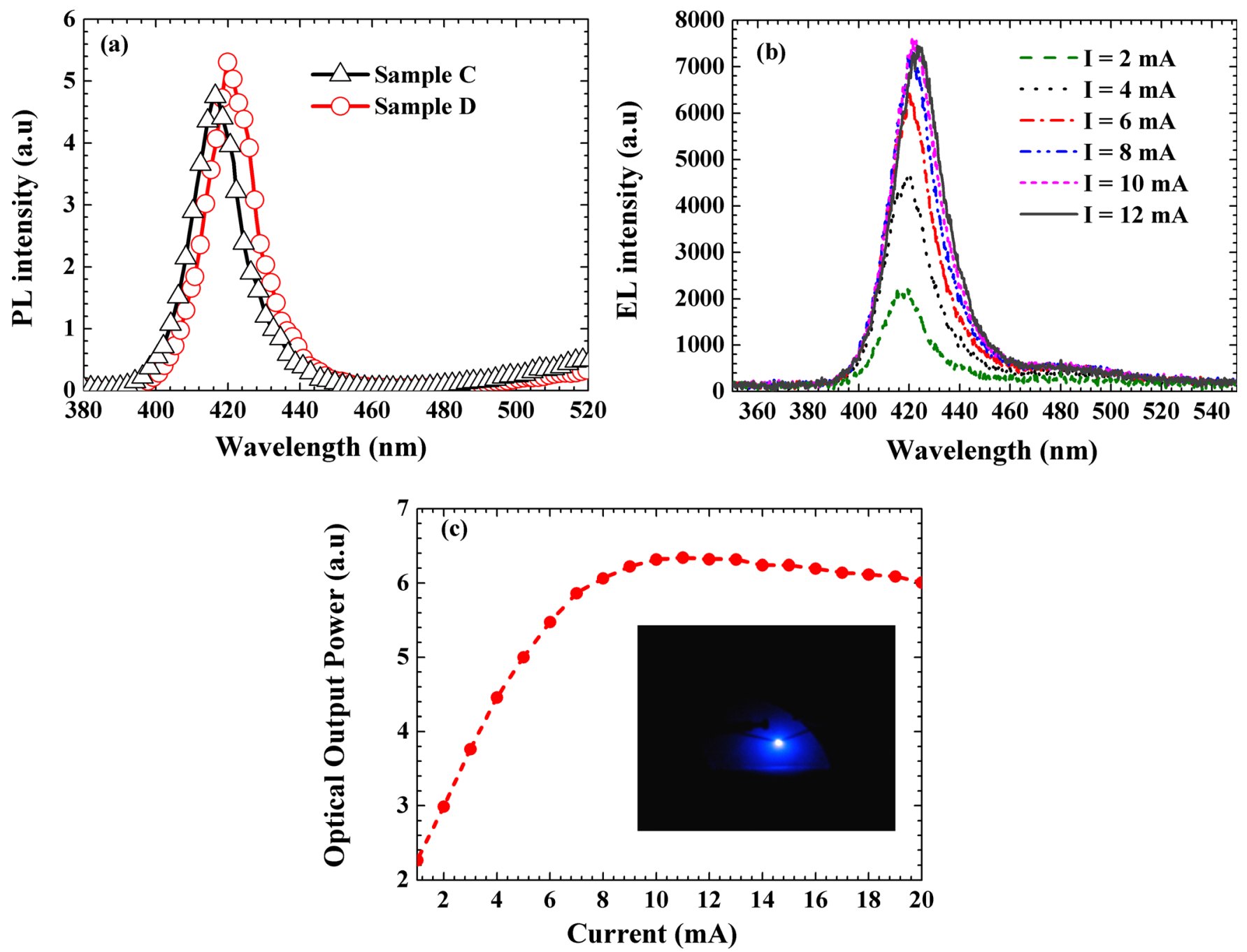

FIG. 4. (a) PL spectra for Samples $C$ and $D$ and (b) EL spectra at various injection current levels for Sample $D$ and (c) optical output power for Sample $D$.

In Sample $D$, the turn-on voltage mainly consists of three components: the pn-junction voltage drop, the voltage drop on the contacts, and the voltage drop across the conduction layer underlying the active region. However, in the conventional InGaN/GaN LED, the underlying conduction layer is the $n-G a N$ layer with the thickness ranging from 2 to $4 \mu \mathrm{m} .{ }^{3,5}$ The mobility of electrons in the $\mathrm{n}-\mathrm{GaN}$ layer is as high as $200 \mathrm{~cm}^{2} / \mathrm{Vs}$ and the electron concentration is typically $1 \times 10^{19} \mathrm{~cm}^{-3}$. Therefore, the voltage drop across the underlying $\mathrm{n}$-GaN layer is negligible. Nevertheless, in Sample $D$, the underlying conduction layer is the 3D hole gas layer with the thickness of only $\sim 50 \mathrm{~nm}$, which significantly reduces the cross-sectional area for the current in the device with a lateral current injection scheme. Moreover, the hole mobility is typically less than $10 \mathrm{~cm}^{2} / \mathrm{Vs}$, which is much lower than that of the electrons, ${ }^{27}$ while the hole concentration is also lower $\left(\sim 5 \times 10^{17} \mathrm{~cm}^{-3}\right)$. Therefore, the voltage drop across the $3 \mathrm{D}$ hole gas layer is quite large, mainly accountable for the large turn-on voltage observed in Fig. 3. Meanwhile, the poor electrical conductance in the 3 DHG $\mathrm{Al}_{x} \mathrm{Ga}_{1-x} \mathrm{~N}$ layer causes the significant current crowding effects, which is also accountable for the high turn-on voltage. $^{5}$ However, the $3 \mathrm{D}$ hole gas generated in the $\mathrm{Al}_{x} \mathrm{Ga}_{1-x} \mathrm{~N}$ layer with a graded AlN composition can be integrated in the InGaN/GaN LED with the p-type GaN layer on top. On one hand, the cross-sectional area for the hole current will be increased, and on the other hand, the overall hole concentration (holes donated by ionized $\mathrm{Mg}$ dopants and $3 \mathrm{D}$ hole gas) can be significantly enhanced, and hence the device performance can be substantially improved. ${ }^{10,28}$

In Fig. 4(a), the PL spectra for both Samples $C$ and $D$ were shown. The FWHM of the PL spectra for Samples $C$ and $D$ are both around $15 \mathrm{~nm}$, which means the excellent crystal quality of the InGaN/GaN quantum wells for Samples $C$ and $D$. The peak emission wavelength is about $\sim 417 \mathrm{~nm}$ and $\sim 420 \mathrm{~nm}$ for Samples $C$ and $D$ at room temperature, respectively. The slightly longer emission wavelength for Sample $D$ is due to the stronger compressive strain from the $\mathrm{Al}_{x} \mathrm{Ga}_{1-x} \mathrm{~N}$ layer underneath the MQWs. ${ }^{17}$ In addition, we have also measured the electroluminescence (EL) from the fabricated device of Sample $D$, which is shown in Fig. 4(b). The emission wavelength at the low current level is peaked at $420 \mathrm{~nm}$, which matches well the PL emission in Fig. 4(a). Besides, we have also measured the EL spectra at various current levels as presented in Fig. 4(b). A red shift of the emission wavelength with increasing injection current levels has been observed and is attributed to the increasing junction temperature during testing. ${ }^{5}$ Meanwhile, the 
integrated optical output power for Sample $D$ is demonstrated in Fig. 4(c). The optical output power increases linearly at a lower current regime and starts to saturate above $12 \mathrm{~mA}$. The saturation of optical power could be due to the significant Joule heating caused by the high device resistance mentioned previously. On the other hand, the EL of Sample $C$ is extremely weak (not detectable in our measurement system) though the PL is observed at room temperature, suggesting Sample $C$ has a low hole concentration in the u-GaN template.

In conclusion, 3D hole gas has been generated in the undoped $\mathrm{Al}_{x} \mathrm{Ga}_{1-x} \mathrm{~N}$ layer with the AlN composition linearly graded from 0.10 to 0.02 along the [0001] growth orientation. The designed structure was further employed as the p-conduction layer to replace the $\mathrm{Mg}$-doped GaN layer in the InGaN/GaN LED. The fabricated device with the 3DHG structure shows an obvious rectifying diode characteristic in IV measurement. More importantly, EL has been observed and detected from the 3D hole gas driven InGaN/GaN LED, which is attributed to the radiative recombination between the electrons injected by the $\mathrm{n}-\mathrm{GaN}$ layer and holes provided by the $3 \mathrm{D}$ hole gas in the $\mathrm{Al}_{x} \mathrm{Ga}_{1-x} \mathrm{~N}$ layer. This work demonstrates that besides conventional Mg-doped p-type $\mathrm{GaN}$, 3D hole gas generated through polarization doping can also be an alternative hole source for InGaN/GaN LEDs. The p-doping free design is promising and could be a potential candidate to achieve better performance in InGaN/GaN LEDs.

This work is supported by the National Research Foundation of Singapore under Grant No. NRF-CRP-62010-2 and NRF-RF-2009-09 and the Singapore Agency for Science, Technology and Research (A*STAR) SERC under Grant No. 112120 2009. The authors would like to thank Dr. Dharmarasu Nethaji and Mr. Yiding Lin for the CV measurements and the useful discussions with them.

${ }^{1}$ S. T. Tan, X. W. Sun, H. V. Demir, and S. P. Denbaars, IEEE Photon. J. 4, 613 (2012).

${ }^{2}$ S. Pimputkar, J. S. Speck, S. P. Denbaars, and S. Nakamura, Nature Photon. 3, 180 (2009).

${ }^{3}$ Y. Ji, Z.-H. Zhang, S. T. Tan, Z. G. Ju, Z. Kyaw, N. Hasanov, W. Liu, X. W. Sun, and H. V. Demir, Opt. Lett. 38, 202 (2013).
${ }^{4}$ Z.-H. Zhang, S. T. Tan, Z. G. Ju, W. Liu, Y. Ji, Z. Kyaw, Y. Dikme, X. W. Sun, and H. V. Demir, J. Display Technol. 9, 226 (2013).

${ }^{5}$ Z.-H. Zhang, S. T. Tan, W. Liu, Z. G. Ju, K. Zheng, Z. Kyaw, Y. Ji, N. Hasanov, X. W. Sun, and H. V. Demir, Opt. Express 21, 4958 (2013).

${ }^{6}$ M. Lachab, D. H. Youn, R. S. Qhalid Fareed, T. Wang, and S. Sakai, Solid State Electron. 44, 1669 (2000).

${ }^{7}$ Y. Y. Zhang and Y. A. Yin, Appl. Phys. Lett. 99, 221103 (2011).

${ }^{8}$ S. J. Lee, S. H. Han, C. Y. Cho, S. P. Lee, D. Y. Noh, H. W. Shim, Y. C. Kim, and S. J. Park, J. Phys. D 44, 105101 (2011).

${ }^{9}$ J. Piprek, Proc. SPIE 8262, 82620E (2012).

${ }^{10}$ J. Simon, V. Protasenko, C. Lian, H. Xing, and D. Jena, Science 327, 60 (2010).

${ }^{11}$ L. Zhang, K. Ding, J. C. Yan, J. X. Wang, Y. P. Zeng, T. B. Wei, Y. Y. Li, B. J. Sun, R. F. Duan, and J. M. Li, Appl. Phys. Lett. 97, 062103 (2010).

${ }^{12}$ Z.-H. Zhang, S. T. Tan, Z. Kyaw, Y. Ji, W. Liu, Z. G. Ju, N. Hasanov, X. W. Sun, and H. V. Demir, Appl. Phys. Lett. 102, 193508-5 (2013).

${ }^{13}$ V. Fiorentini, F. Bernardini, and O. Ambacher, Appl. Phys. Lett. 80, 1204 (2002).

${ }^{14}$ C. Buchheim, R. Goldhahn, G. Gobsch, K. Tonisch, V. Cimalla, F. Niebelschütz, and O. Ambacher, Appl. Phys. Lett. 92, 013510 (2008).

${ }^{15}$ K. Tonisch, C. Buchheim, F. Niebelschütz, A. Schober, G. Gobsch, V. Cimalla, O. Ambacher, and R. Goldhahn, J. Appl. Phys. 104, 084516 (2008).

${ }^{16}$ S. Helkman, S. Keller, Y. Wu, J. S. Speck, S. P. DenBaars, and U. K. Mishra, J. Appl. Phys. 93, 10114 (2003).

${ }^{17}$ Z. G. Ju, S. T. Tan, Z.-H. Zhang, Y. Ji, Z. Kyaw, Y. Dikme, X. W. Sun, and H. V. Demir, Appl. Phys. Lett. 100, 123503 (2012).

${ }^{18}$ D. K. Schroder, Semiconductor Material and Device Characterization, 2nd ed. (John Wiley \& Sons, Hoboken, 1998).

${ }^{19}$ D. Jena, S. Heikman, D. Green, D. Buttari, R. Coffie, H. Xing, S. Keller, S. DenBaars, J. S. Speck, U. K. Mishra, and I. Smorchkova, Appl. Phys. Lett. 81, 4395 (2002).

${ }^{20}$ S. Acar, S. B. Lisesivdin, M. Kasap, S. Özçelik, and E. Özbay, Thin Solid Films 516, 2041 (2008).

${ }^{21}$ T. Zimmermann, M. Neuburger, M. Kunze, I. Daumiller, A. Denisenko, A. Dadgar, A. Krost, and E. Kohn, IEEE Electron Dev. Lett. 25, 450 (2004).

${ }^{22}$ A. Nakajima, Y. Sumida, M. H. Dhyani, H. Kawai, and E. M. S. Narayanan, Appl. Phys. Express 3, 121004 (2010).

${ }^{23}$ J. Piprek, Nitride Semiconductor Devices Principles and Simulation (Wiley-VCH Verlag GmbH \& Co. KGaA, Weinheim, 2007).

${ }^{24}$ C. G. Van de Walle and J. Neugebauer, J. Appl. Phys. 95, 3851 (2004).

${ }^{25}$ D. G. Zhao, S. Zhang, W. B. Liu, X. P. Hao, D. S. Jiang, J. J. Zhu, Z. S. Liu, H. Wang, S. M. Zhang, H. Yang, and L. Wei, Chin. Phys. B 19, 057802 (2010).

${ }^{26}$ See supplementary material at http://dx.doi.org/10.1063/1.4858386 of the simulated energy band diagrams and carrier concentration for Samples $A$ and $B$.

${ }^{27}$ J. Hertkorn, S. B. Thapa, T. Wunderer, F. Scholz, Z. H. Wu, Q. Y. Wei, F. A. Ponce, M. A. Moram, C. J. Humphreys, C. Vierheilig, and U. T. Schwarz, J. Appl. Phys. 106, 013720 (2009).

${ }^{28}$ L. Zhang, X. C. Wei, N. X. Liu, H. X. Lu, J. P. Zeng, J. X. Wang, Y. P. Zeng, and J. M. Li, Appl. Phys. Lett. 98, 241111 (2011). 